\title{
Corrigendum
}

\section{Media Freedom and the Institutional Underpinnings of Political Knowledge-CORRIGENDUM}

\author{
MARTIJN SCHOONVELDE
}

doi: http://dx.doi.org/10.1017/psrm.2013.18, Published online by Cambridge University Press 8 October 2013

In the above publication the incorrect version of figure 2 has been published. The author apologises for this error and the correct figure 2 is shown below.

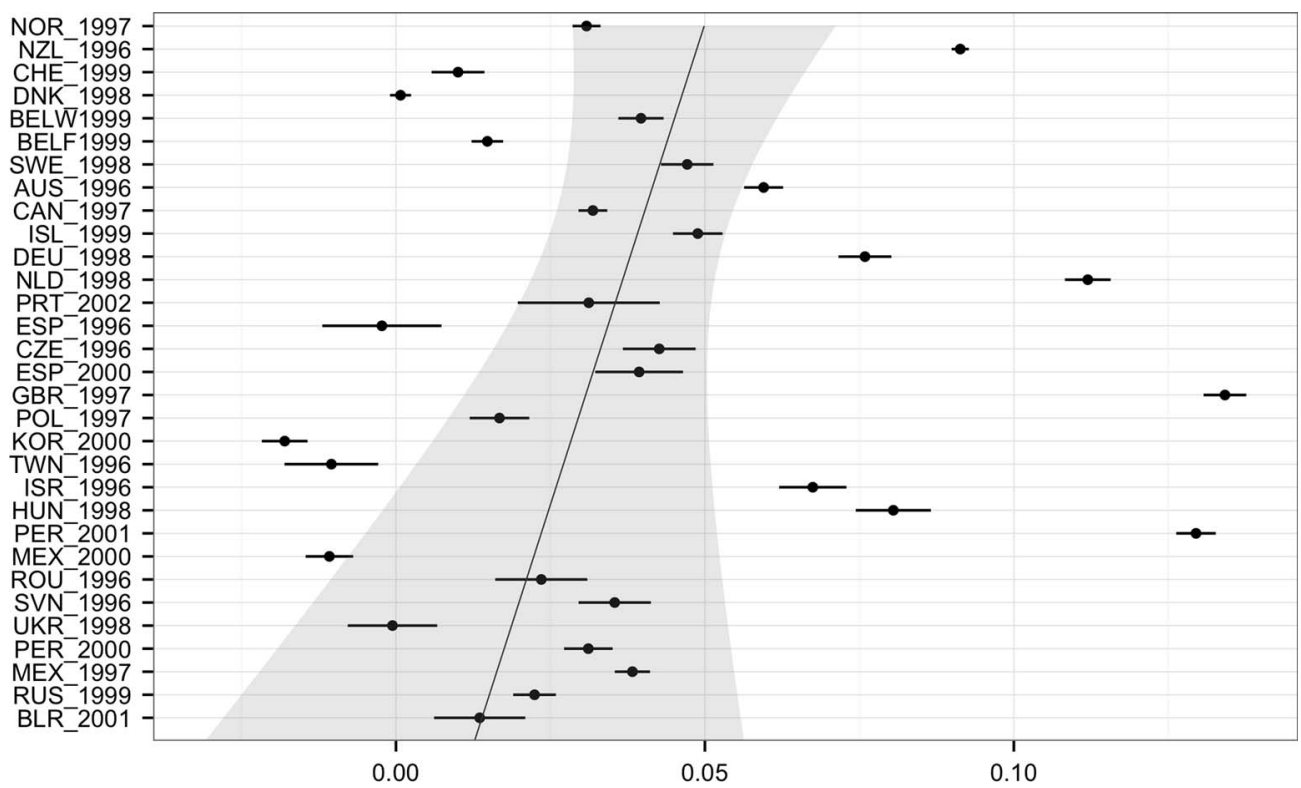

Fig. 2. Conditional effects of Education across elections and countries

The author would also like to correct the paragraph on page 12 that describes figure 2 .

Figure 2 displays the estimated conditional effects (and their 95 percent confidence intervals) for all countries, sorted from lowest (Belarus in 2001) to highest (Norway in 2007) Media Freedom. Even though the conditional effects do not neatly line up in order, there is some evidence that as Media Freedom increases, so does the effect of Education on Political Knowledge (yet the displayed linear regression line of the 
conditional effects of Education on Media Freedom fails to reach significance $(\beta=0.04$, se $=0.03, p=0.19)$ because of the large variation in the random effects). In anything, the plot paints an interesting picture of varying conditional effects, in which Education ranges from having slightly negative effects on political knowledge (for example, in Korea, Taiwan and in Mexico in 2000) to having sizable positive effects. To illustrate, in New Zealand a university-educated individual is about 8 percentage points more knowledgeable about politics than a counterpart with only a secondary school education. And in Germany, education alone moves an individual about half a standard deviation up the political knowledge distribution.

\section{REFERENCE}

Martijn, Schoonvelde. Media Freedom and the Institutional Underpinnings of Political Knowledge. Political Science Research and Methods, available on CJO2013. doi:10.1017/psrm.2013.18. 